\title{
A two-year analysis of uterine rupture in pregnancy
}

\section{Sunanda N.*, Priya Ranganth}

Department of Obstetrics and Gynaecology, Mysore Medical College and Research Institute, Mysore, Karnataka, India

Received: 10 September 2016

Accepted: 05 October 2016

\author{
*Correspondence: \\ Dr. Sunanda N, \\ E-mail: sunanda_n@rediffmail.com
}

Copyright: (c) the author(s), publisher and licensee Medip Academy. This is an open-access article distributed under the terms of the Creative Commons Attribution Non-Commercial License, which permits unrestricted non-commercial use, distribution, and reproduction in any medium, provided the original work is properly cited.

\begin{abstract}
Background: The aim of our study is to analyze cases of rupture uterus in pregnancy by evaluating the risk factors, type and site of rupture, management, and maternal and perinatal outcome associated with it at a tertiary care hospital, allied with Mysore medical college and research institute, Mysore.

Methods: A retrospective study was conducted in the department of obstetrics and gynecology at Cheluvamba hospital allied with Mysore medical college and research institute, Mysore from January 2013- December 2014. All patients attending obstetric emergency care unit at Cheluvamba hospital, Mysore from January 2013 to December 2014 were included in the study. Cases in which emergency caesarean section were performed for suspected rupture uterus was isolated. Amongst them, the relevant history, intra-operative findings and postoperative morbidity and mortality was studied. Those cases in which successful trial of labor was given was also examined and documented.

Results: A total of 28,574 deliveries were conducted at Cheluvamba hospital for the year 2013. During this period, $7455(26 \%)$ cases of lower segment caesarean section were performed. Amongst them, 20 cases of complete uterine rupture were seen with 147 cases of incomplete rupture or scar dehiscence. 16 cases $(80 \%)$ of them had a prior scar and the remaining 4 cases $(20 \%)$ had primary or non-scar rupture. Thus the incidence of scar rupture is $0.26 \%$. The incidence of scar dehiscence was 1.97\%. 144 cases had VBAC. The incidence of VBAC in our institution was $1.93 \%$. $95 \%$ of cases were multigravida, $30 \%$ were unbooked and $65 \%$ were referred. The main risk factor was scarred uterus $(80 \%)$. However $20 \%$ of cases, primary rupture were seen due to injudicious use of oxytocics (10\%) grand multiparity $(5 \%)$ and forceps in delivery (1\%). Repair of uterus was done successfully in 16 cases $(80 \%), 4$ cases had to undergo peripartum hysterectomy (20\%). There were 2 maternal deaths and 7 still births.

Conclusions: Rupture uterus is still a significant cause of maternal and perinatal morbidity and mortality. Early diagnosis, immediate resuscitation with rapid replacement of blood loss is key to management of such cases.
\end{abstract}

Keywords: Scar dehiscence, Uterine rupture, VBAC

\section{INTRODUCTION}

Uterine rupture although rare, is one of the life threatening obstetric complication with grave sequelae to both mother and the fetus. Incidence of rupture uterus varies from $0.3 / 1000$ to $7 / 1000$ deliveries in India accounting for $5 \%$ to $10 \%$ of all maternal deaths. ${ }^{1}$ The incidence in developed and developing countries varies from 1 in 250 to 1 in 5000 deliveries depending upon standard of obstetric care and the population dealt with. In a WHO systematic review of maternal mortality and morbidity, the prevalence of uterine rupture in cases of previous caesarean section was found to be $1 \%{ }^{2}$

Uterine rupture refers to complete disruption of all uterine layers, including the serosa. By comparison, uterine dehiscence generally refers to an incomplete, and frequently clinically occult, uterine scar separation where the serosa remains intact. Most common cause of uterine rupture include previous scar giving way. Other causes like obstructed labor, injudicious use of oxytocics, previous myomectomy scar, uterine anomaly, direct 
trauma to uterus and rarely concealed abruption can also cause uterine rupture. Uterine rupture manifests as fetal distress, fetal death, and maternal tachycardia, bleeding per vagina, haematuria and loss of station of presenting part. The initial signs and symptoms are however, nonspecific, a condition that makes diagnosis difficult and sometimes delays definitive therapy. The best chance of detecting uterine rupture lies in careful and continuous monitoring of uterine contractions and fetal wellbeing during labor. Continuous cardiotocography with intra uterine pressure measurements may help to identify scar rupture early and may be of value especially in those who have an oxytocin infusion. Maternal outcome mainly depends on the integrity of previous scar, cause and site of rupture, interval between rupture and surgery and early detection and prompt referral. High perinatal mortality of $80-95 \%$ is seen in these cases. ${ }^{3}$

The objective of our study is to evaluate the patients with complete uterine rupture which occurred during pregnancy. The risk factors, type and site of rupture, maternal and perinatal outcomes, and complications associated with it are evaluated with the aim of devising appropriate interventions to decrease maternal and perinatal morbidity and mortality.

\section{METHODS}

It is a retrospective study of patients with uterine rupture attending Cheluvamba hospital, a tertiary care hospital, allied with Mysore Medical College and Research Institute. A study period of 2 years, from January 2013 to December 2014 is chosen. All patients attending obstetric emergency care unit during the study period were included in the study.

Cases in which emergency caesarean section were performed for suspected rupture uterus were isolated from the total number of cases attending out Patient department. Their relevant history documented. Intraoperative findings regarding site and type of rupture, presence of hemoperitoneum, mode of management and associated injury to adjacent organs were noted. Postoperative maternal and neonatal morbidity and mortality was studied. Those cases in which successful trial of labor was given was also examined and documented.

\section{Inclusion criteria}

All cases attending outpatient department of Cheluvamba hospital from January 2013 to December 2014.

\section{Statistical method}

Data was entered into epidata and analysed using epi info. Descriptive statistics was used to generate results.

\section{RESULTS}

A total of 20 cases of rupture uterus were recorded for the period of two years. During this period, the total numbers of deliveries were 28,574. Out of 28574 deliveries, 7455 underwent emergency caesarean section. The rate of caesarean section in our hospital during the study period was $26.09 \%$.

Table 1: Incidence of VBAC.

\begin{tabular}{|ll|}
\hline & Number \\
\hline Total LSCS & 7455 \\
\hline Scar rupture & 16 \\
\hline Non-scar rupture & 4 \\
\hline Scar dehiscence & 147 \\
\hline VBAC & 144 \\
\hline
\end{tabular}

20 cases of rupture uterus and 147 cases of scar dehiscence were seen. Hence the incidence of scar rupture and dehiscence in our study is $0.26 \%$ and $1.97 \%$. 144 cases had VBAC. The incidence of VBAC in our institution was $1.93 \%$ (Table 1).

Table 2: Age distribution.

\begin{tabular}{|lll|}
\hline Age (years) & Number & Percentage $(\%)$ \\
\hline $15-25$ & 11 & 55 \\
\hline $25-35$ & 9 & 45 \\
\hline $35-45$ & 0 & 0 \\
\hline
\end{tabular}

Most of the women were in the age group 15-25 years, 11 cases $(55 \%)$. The remaining 9 cases $(45 \%)$ belonged to the age group between 25 and 35 . There were no cases beyond 35 years with scar rupture (Table 2).

Table 3: Antenatal care at primary health care center.

\begin{tabular}{|lll|}
\hline Antenatal care & Number & Percentage \\
\hline Booked & 14 & 70 \\
\hline Unbooked & 6 & 30 \\
\hline
\end{tabular}

14 cases $(70 \%)$ of the cases were booked compared to 6 cases $(30 \%)$ that were unbooked. Most of these cases were referred and hence had received regular ANC at a nearby Primary Health care center or a $\mathrm{CHC}$ and were referred here in labour (Table 3).

Table 4: Gravida distribution in patients.

\begin{tabular}{|lll|}
\hline Parity & Number & Percentage \\
\hline Primi & 1 & 5 \\
\hline Gravida 2 & 13 & 65 \\
\hline$>$ Gravida 2 & 6 & 30 \\
\hline
\end{tabular}

Majority of patients were second gravida, 13 cases $(65 \%)$. 6 cases $(30 \%)$ were gravida three and beyond. Only one case was a primigravida (Table 4). 
Table 5: Scar distribution.

\begin{tabular}{|lll|}
\hline Previous section & Number & Percentage \\
\hline None & 4 & 20 \\
\hline 1 & 13 & 65 \\
\hline $2 / 3$ & 3 & 15 \\
\hline
\end{tabular}

13 cases $(65 \%)$ had previous one scar. 3 patients $(15 \%)$ had previous 2 or more scars. Non-scar rupture was seen in 4 cases $(20 \%)$ (Table 5).

Table 6: Intervention.

\begin{tabular}{|lll|}
\hline Intervention & Number & Percentage \\
\hline Nil & 14 & 70 \\
\hline D and C & 4 & 20 \\
\hline Oxytocin & 2 & 10 \\
\hline PGE2 & 0 & 0 \\
\hline
\end{tabular}

14 patients $(70 \%)$ of those who had rupture uterus did not have any induction or augmentation of labour. 4 cases $(20 \%)$ had prior history of dilatation and curettage. 2 cases $(10 \%)$ had syntocinon augmentation. None of the cases were induced with PGE2 gel (Table 6).

Table 7: Rupture cases.

\begin{tabular}{|lll|}
\hline Site & Number & Percentage \\
\hline Primary & 5 & 25 \\
\hline Previous scar & 15 & 75 \\
\hline
\end{tabular}

Rupture at the previous scar site was seen in 15 cases (75\%). Primary or non-scar rupture was seen in 5 cases $(25 \%)$. One case had a prior scar but the site of rupture was at the fundus of communicating horn of a bicornuate uterus.one case of arcuate uterus was seen (Table 7).

Table 8: Associated comorbidity in patients.

\begin{tabular}{|lll|}
\hline Associated comorbidity & Number & Percentage \\
\hline Bladder injury & 6 & 30 \\
\hline Bowel injury & 1 & 5 \\
\hline Shock & 7 & 35 \\
\hline DIC & 5 & 25 \\
\hline Stay $>7$ days & 9 & 45 \\
\hline $\begin{array}{l}\text { Bilateral uterine artery } \\
\text { ligation }\end{array}$ & 5 & 25 \\
\hline Peripartum hysterectomy & 5 & $25 \%$ \\
\hline
\end{tabular}

6 cases $(30 \%)$ were associated with bladder and 1 Case associated with bowel injury. In all of the cases primary repair was done. 7 cases $(35 \%)$ had shock and 5 cases $(25 \%)$ went into DIC. In 5 cases $(25 \%)$ bilateral uterine artery ligation done and 5 cases $(25 \%)$ underwent peripartum hysterectomy (Table 8).
Table 9: Mortality distribution.

\begin{tabular}{|lll|}
\hline Mortality & Number & Percentage \\
\hline Maternal & 2 & $10 \%$ \\
\hline Fetal & 7 & $35 \%$ \\
\hline
\end{tabular}

Maternal mortality was seen in 2 cases (10\%) and fetal mortality seen in 7 cases $(35 \%)$ (Table 9$)$.

\section{DISCUSSION}

In the present study, the incidence of uterine rupture is $0.26 \%$ similar to studies done at other referral hospitals in India. A study done by Singh A and Sunitha K et al showed an incidence of $0.35 \%$ and $0.23 \%$ respectively similar to the present study. ${ }^{4,5}$ The incidence is lower for developed than the less developed countries. Among the developing countries, the incidence varied from 1 in 124 $(0.8 \%)$ in Ghana $0.76 \%$ in Uganda $0.74 \%$ in Pakistan $0.9 \%$ in Nepal and $2.8 \%$ in Ethiopia. ${ }^{6-10}$ Studies from developed countries showed incidences recorded as $0.035 \%{ }^{11}$ This wide variation in incidence between developed and developing countries are due to socio economic factors, cultural practices and lack of access to antenatal and intrapartum care.

Majority of cases in our study belonged to age group between 15 and 25 years, 11 cases (55\%) and majority of patients were second gravida, 13 cases $(65 \%)$ similar to other studies.

Table 10: Scar rupture comparison with various studies.

\begin{tabular}{|llll|}
\hline $\begin{array}{l}\text { Present } \\
\text { study }\end{array}$ & $\begin{array}{l}\text { Sahu L et } \\
\mathrm{al}^{1}\end{array}$ & $\begin{array}{l}\text { Sunita } \\
\text { K et } \\
\text { al }^{5}\end{array}$ \\
\hline $\begin{array}{l}\text { Scar repair } \\
\text { Subtotal } \\
\text { hysterectomy }\end{array}$ & $75 \%$ & $58.51 \%$ & $68 \%$ \\
\hline Bladder repair & $30 \%$ & $41.49 \%$ & $32 \%$ \\
\hline
\end{tabular}

In a study done by Sahu L at JIPMER Pondicherry in the year 2006 , scar rupture was seen in $50.60 \%$ of the cases. ${ }^{1}$ In our study the incidence of scar rupture is slightly higher $(80 \%)$ compared to other similar studies. ${ }^{4,5}$ However rupture of previous caesarean scar still remains the most common cause of scar rupture in all of them. Among the cases with non-scar rupture, injudicious use of oxytocics was the most common cause in our study.

Amongst the operative interventions made, in most of the cases scar repair was done as a primary resort $(75 \%)$, subtotal hysterectomy was done in $25 \%$ and $30 \%$ of cases had bladder injury which corresponds to study done by Sunita $\mathrm{K}$ et al. ${ }^{5}$ however the incidence if bladder injury is very high in our study compared to similar studies. 
Maternal mortality is higher in our study compared to our study probably due to higher incidence of referral compared to similar studies. Perinatal mortality is similar to study done by Sunita K et al.

Table 11: Mortality comparison with various studies.

\begin{tabular}{|llll|}
\hline & $\begin{array}{l}\text { Present } \\
\text { study }\end{array}$ & $\begin{array}{l}\text { Sahu L et } \\
\text { al }^{1}\end{array}$ & $\begin{array}{l}\text { Sunita } \\
\text { K et } \\
\text { al }^{5}\end{array}$ \\
\hline Maternal mortality & $10 \%$ & $2.76 \%$ & Nil \\
\hline Perinatal mortality & $35 \%$ & $83 \%$ & $58 \%$ \\
\hline
\end{tabular}

\section{CONCLUSION}

Ruptured uterus still remains one of the serious obstetric complications. Lack of health information, illiteracy, poor antenatal care, poverty, home delivery by traditional birth attendants and delay in referrals all contributes to uterine rupture. Most of the causes are however preventable. Good antenatal care, appropriate counseling of patients with history of previous caesarean Section for hospital delivery, training of skilled birth attendant can decrease the incidence of scar ruptures. Also, injudicious use of oxytocics appears to be the most common cause for non-scar rupture in labor which should be strongly condemned.

Funding: No funding sources Conflict of interest: None declared

Ethical approval: The study was approved by the Institutional Ethics Committee

\section{REFERENCES}

1. Sahu LA. 10 year analysis of uterine rupture at a teaching institution. $\mathbf{J}$ Obstet Gynecol India. 2006;5(6):502-6.

2. Justus Hofmeyr G, Say L. Systematic review: WHO systematic review of Maternal mortality and morbidity: the prevalence of uterine rupture. BJOG: An International Journal of Obstetrics \& Gynaecology. 2005;112:1221-8.

3. Mahbuba, Alam IP. Uterine rupture - experience of 30 cases at Faridpur Medical college Hospital. Faridpur Med Coll J. 2012;7(2):79-81.

4. Singh A, Shrivastava C. Uterine Rupture: Still a Harsh Reality. Journal of obstetrics and gynaecology of India. 2015;65(3):158-61.

5. Sunitha K, Indira I, Suguna P. Clinical Study of Rupture Uterus - Assessment of Maternal and Fetal Outcome. Journal of Dental and Medical Sciences. 2015;14(3):39-45.

6. Fofie CO, Baffoe P. A Two-Year Review of Uterine Rupture in a Regional Hospital. Ghana Med J. 2010;44(3):98-102.

7. Mukasa PK, Kabakyenga J. Uterine rupture in a teaching hospital in Mbarara, western Uganda, unmatched case- control study. Reprod Health. 2013;10:29.

8. Rizwan N, Abbasi RM. Uterine rupture, frequency of cases and fetomaternal outcome. J Pak Med Assoc. 2011;61(4):322-4.

9. Padhye SM. Rupture of the pregnant uterus: a 20 year review. Kathmandu Univ Med J. 2005;3:234-8.

10. Omole-Ohonsi, Attah. Uterine rupture: risk factors and pregnancy outcome. Gynecol Obstetric. 2011;1:1.

Cite this article as: Sunanda N, Priya R. A two-year analysis of uterine rupture in pregnancy. Int J Reprod Contracept Obstet Gynecol 2016;5:3983-6. 